\title{
Espacios de pobreza en la periferia urbana y suburbios interiores de la Ciudad de México. Las desventajas acumuladas
}

Adrián G. Aguilar. Universidad Nacional Autónoma de México (unAm), México. Flor M. López. Universidad Nacional Autónoma de México (UnAM), México.

RESUMEN | Las diferenciaciones socioespaciales en el espacio urbano nos remiten a la concentración geográfica de la pobreza. Alrededor de este tema, sin embargo, no se encuentran estudios de carácter local sobre espacios pobres en las ciudades, en los cuales se relacionen las problemáticas socioeconómicas de los grupos más desprotegidos con espacios urbanos específicos. Los barrios pobres tienden a agruparse y conforman espacios o franjas urbanas dominadas por situaciones de exclusión social. Este estudio analiza las principales características y desventajas de las familias pobres que habitan estos espacios en los suburbios y la periferia de la Ciudad de México, a través de los resultados de 329 encuestas aplicadas en ese territorio. Se da particular atención a la medida de los niveles de pobreza de sus habitantes, que abarca desde población no pobre, pobres moderados, pobres extremos y pobres indigentes. Para tal medición se utilizan índices como el acceso a satisfactores básicos, la situación laboral y la cohesión social, distinguiendo las colonias pobres según su localización en un suburbio interior o en la periferia urbana.

palabras Clave | barrios pobres, Ciudad de México, acumulación de desventajas, periferia urbana, suburbio interior.

ABSTRACT | The socio-spatial differentiation in the urban space refers to the geographic concentration of poverty. In the literature there is an absence of studies about poverty spaces in cities, relating the socio-economic situation of the underprivileged to particular urban spaces. Poor neighbourhoods tend to group together in clusters dominated by situations of social exclusion. This study presents an analysis of the main features and disadvantages of families living in poor spaces in Mexico City through the results of 329 surveys applied in poor neighbourhoods of the urban periphery and the inner suburb. Special attention is given to the measure of poverty levels, identifying four categories: non-poverty, moderate poverty, extreme poverty and indigence. This measuring is based on access to basic needs, labour condition, and social cohesion according to peripheral and suburban location.

KEY WORDS | poor neighbourhoods, Mexico City, accumulated disadvantages, urban periphery, inner suburb. 


\section{Presentación}

Este trabajo tiene como propósito avanzar en el conocimiento de los actuales espacios pobres en la Ciudad de México, a través del análisis de un grupo de siete asentamientos pobres de su suburbio interior y su periferia urbana. Se presentan los resultados de la aplicación de un cuestionario diseńado para este estudio, que tuvo por objetivo conocer la situación socioeconómica de la población, sus principales carencias en términos de necesidades básicas, su inserción laboral, y las principales relaciones sociales que indican algún grado de cohesión social al interior de los barrios seleccionados. Con este material se da un diagnóstico de los niveles de pobreza prevalecientes en dichos asentamientos. Para ello se identifican, en primer lugar, cuatro categorías socioeconómicas en sus habitantes: no pobres, pobres moderados, pobres extremos y pobres indigentes; luego, el peso específico que tiene el carácter periférico de los asentamientos; y finalmente, la debilidad de las relaciones sociales de los grupos residentes. El principal aporte de este trabajo es enfatizar la dimensión territorial de la pobreza urbana. Para ello destaca la acumulación de desventajas en cada lugar y cómo la condición de localización influye en el agravamiento de situaciones de inclusión desventajosa. En esa línea de análisis, se agrupan las colonias encuestadas en dos tipos de localizaciones, suburbio interior y periferia urbana, como espacios de pobreza diferenciados.

\section{Espacios de pobreza y periferia urbana}

La diferenciación socioeconómica en el espacio urbano tiende a reproducirse en el tiempo y con ello se perpetúan las desventajas de los grupos más desfavorecidos, esto es, localizaciones con un hábitat muy precario, pobre dotación de infraestructura urbana y baja presencia de servicios urbanos. Agrava esta situación la crisis económica por la que atraviesan los países en la región latinoamericana, que impide que los gobiernos de las grandes metrópolis respondan a las exigencias de viviendas y dotación de servicios urbanos en las zonas más pobres. Se trata de una coyuntura que agudiza las desventajas de estas zonas y funciona como mecanismo de exclusión social para los grupos residentes.

En los análisis de los barrios pobres de las ciudades de América Latina realizados a lo largo de los últimos cuarenta años destacan dos perspectivas centrales: la primera, en los ańos sesenta, desarrollada a partir del marco conceptual de la marginalidad social; y la segunda, en la década de los noventa, que tiene como base una concepción negativa de los efectos del modelo económico neoliberal en nuestras sociedades.

En el primer caso, en los sesenta, se definía la marginalidad urbana por la ausencia de un rol económico articulado con el sistema de producción industrial; un sistema en el cual un amplio contingente de fuerza de trabajo urbano, al no estar integrado en las actividades productivas de manera estable y con remuneraciones adecuadas, debe aceptar vivir en la precariedad de barrios pobres. Es decir, se definía la marginalidad por la presencia de sectores sociales al margen de los procesos económicos y políticos oficiales (Lomnitz, 1980, p. 17; Duhau, 1998, p. 34; Ward, 2004, p. 184; 
Ziccardi, 2008, p. 73). En estos grupos marginales destacaban los migrantes rurales (Muñoz, Oliveira \& Stern, 1980), que ocupaban y se hacinaban en los tugurios y casonas del centro de la ciudad, para luego poblar la periferia. De esta época son los reconocidos estudios de Lomnitz (1980) sobre redes de intercambio, y los de Lewis (1964) sobre la "cultura de la pobreza" en la Ciudad de México. La vivienda era la principal reivindicación de estos grupos, que organizaron movimientos sociales en varios países; sin embargo, los bajos ingresos de las familias que los integraban les impedían participar en el mercado habitacional, incluso el subsidiado. En tales condiciones, muchos de esos grupos fueron expulsados de sus barrios originales a las periferias lejanas, donde crearon barrios populares de autoconstrucción (Ziccardi, 2008, p. 82; Duhau, 1998, p. 120).

En el caso de los estudios sobre los efectos de la aplicación extendida del modelo económico neoliberal, muchos se han referido a las profundas transformaciones sociales que a partir de los años 1980 dicho modelo ha generado en América Latina. Estos trabajos centran su atención en el proceso de empobrecimiento de amplios sectores de la población durante el periodo iniciado en esa década. También enfocan su análisis en la "nueva pobreza" de las clases medias, que vieron cómo se deterioraban sus condiciones de vida durante esos años; y en las transformaciones que enfrentaron los sectores tradicionalmente pobres -los llamados "pobres estructurales"- en la región, que sufrieron una intensificación de sus condiciones de privación y llegaron al fondo de la estratificación social (véase Kaztman \& Wormald, 2002; Eguía, 2004; Enríquez, 2003; Bayón \& Saraví, 2006, p. 56).

En México, diversos procesos confluyen para explicar la concentración y mayor profundidad de la pobreza en el espacio urbano, a la vez que bloquean la movilidad socioeconómica y residencial de los pobres; entre ellos, bajos niveles educativos, precariedad laboral, desempleo, falta de protección social, inadecuada infraestructura, falta de acceso a equipamiento, redes sociales inexistentes o deficientes y disminución de la capacidad de asociación y gestión colectiva, todas desventajas de carácter concentrado y acumulativo (Enríquez, 2003; Bayón, 2008, p. 128). Tal escenario ha producido severos ajustes en el ámbito de la vida social y familiar, que se explican a través de un proceso de desventajas acumuladas. Este concepto alude al impacto que la exclusión laboral ha provocado en distintos ámbitos de la vida social. Lo que hoy se observa es la suma o acumulación del déficit y deterioro de las condiciones de sobrevivencia, un desgaste que resta a los pobres capacidad de acción y de reacción y los hace mucho más vulnerables (González de la Rocha, 2004, p.194; 2006, pp. 108-112).

Frente al agravamiento de la pobreza urbana, y particularmente en cuanto a la inserción de las personas y familias en los sistemas de bienestar y el mercado laboral, hay autores que proponen adoptar el enfoque de la exclusión social, que representa una visión más integral de la vulnerabilidad social. Representante de esta aproximación es Saraví (2006), para quien "no se trata simplemente de un problema del mercado laboral, sino de la crisis de los mecanismos de integración social; una integración precaria y débil al mercado de trabajo asociada con otras desventajas, como el acceso a la educación, a la vivienda, a los servicios de salud, a un ingreso decente, a niveles aceptables de participación social" (p. 25). Todo lo anterior representa los 
eslabones de un proceso de acumulación de desventajas que conduce a un estado final de desvinculación respecto de la sociedad, es decir, de exclusión social.

Dos aspectos hay que destacar de los barrios pobres en esta nueva fase: primero, la concentración de pobres en determinados barrios; y segundo, la localización periférica de la pobreza. A continuación nos referimos brevemente a estos dos aspectos.

La formación de los espacios pobres. En estos barrios se concentra un marcado nivel de privación material, en contraste con los barrios de mayor nivel socioeconómico, con una población que vive en condiciones de extrema pobreza. De acuerdo con Katzman (2001, p. 181), esta precariedad se refuerza por varias vías: primero, las redes vecinales son ineficaces para conseguir empleo u oportunidades de capacitación; segundo, hay dificultad para mantener una organización vecinal básica; tercero, los niños y jóvenes carecen de modelos de rol exitosos y de oportunidades de exposición a esos modelos; y cuarto, las situaciones de desempleo crónico aumentan la predisposición a explorar fuentes ilegítimas de ingreso. En el caso del acceso al trabajo, se hace cada vez más difícil, pues actualmente se exigen niveles educativos que aseguren competencia, y el lugar donde viven estas poblaciones -las estigmatizadas periferias urbanas- puede influir negativamente. Por otra parte, suele existir una mala conexión entre la localización de los grupos de bajos ingresos (en zonas periféricas) y la localización de empleo; hay indicios de que los barrios de ingresos bajos pueden estar convirtiéndose en barrios social y económicamente más aislados que en el pasado (Roberts, 2006, p. 203). Para Katzman (2001), el reciente escenario social y económico ha creado condiciones que favorecen el surgimiento de barrios que se acercan mucho a los rasgos típicos del gueto urbano (p. 182); la pobreza no es inherente al lugar, sino producto de una historia de ese espacio urbano y de las relaciones de poder entre actores que se sucedieron en ese lugar en un momento determinado, y que llevaron a legitimar una solución (política) confinada a esa escala y localización (p. 44).

La periferización de la pobreza. Respecto a la localización espacial de estos grupos sociales, existe una marcada tendencia a encontrarlos cada vez más en la periferia urbana de las metrópolis latinoamericanas (Janoschka, 2005, pp. 101-104; Winchester, 2008, p. 35; Ariza \& Solís, 2009, pp. 200-203; Aguilar \& López, 2013). Se trata de asentamientos recientes producto del proceso de periurbanización, muchos de ellos de carácter informal y con déficit marcados de servicios públicos. La recuperación de zonas centrales y la revaloración de espacios rehabilitados han empujado a los grupos pobres a buscar medios informales para resolver su problema de falta de vivienda, y lo han hecho en terrenos baratos con difícil acceso y con alto riesgo ambiental. Estos espacios pobres se distribuyen, así, en la periferia más alejada de las ciudades y con las mayores carencias; se trata generalmente de las peores localizaciones, donde los asentamientos forman agrupaciones en una situación muy marcada de exclusión social. Todo ella ha dado lugar a un proceso de "periferización de la pobreza"1.

En referencia a Montevideo, Kaztman (2001, p. 181) menciona la formación los nuevos barrios 
Por lo tanto, el escenario que tenemos es la presencia de espacios de pobreza en localizaciones centrales y también periféricas, con diferentes grados de pobreza y de desventajas acumuladas. En las siguientes secciones ejemplificaremos esta cuestión para el caso de la Ciudad de México.

\section{Periurbanización y espacios de pobreza en la Ciudad de México}

Respecto del tema de las condiciones de pobreza urbana en México, varios estudios señalan cómo ellas se han agravado y profundizado y cómo los pobres enfrentan cada vez más una situación de sobrevivencia muy difícil. Tal situación sería resultado de un generalizado deterioro de los niveles de vida, de las dificultades de inserción en el mercado de trabajo, del debilitamiento de las estructuras de protección social en el sistema de salud y de educación, y de las mínimas posibilidades de acceso al suelo para tener un espacio donde vivir (Enríquez, 2003; Bayón, 2008; Saraví, 2011).

Los datos tienden a mostrar una alta concentración de población pobre en la Ciudad de México, y un predominio de grupos con graves carencias sociales en las zonas periféricas. El Consejo Nacional de Evaluación de la Política de Desarrollo Social (CONEVAL), institución creada en 2005, de nivel federal, señala que para el Distrito Federal, los resultados de la evolución de la pobreza de 2000 a 2010 muestran que ella pasó de 3,7 millones de personas en el primer año, a 4,5 millones en el segundo, lo que representa un aumento de la población en pobreza de 848.340 personas en diez ańos (coneval, 2010)2. En esencia, los niveles de pobreza alcanzan alrededor del $50 \%$ de la población en el Distrito Federal.

En segundo lugar, es interesante señalar las mediciones de pobreza del Consejo de Evaluación del Desarrollo Social del Distrito Federal (Evalúa DF) en el Distrito Federal, con una sobremuestra que aplicó el Instituto Nacional de Estadística, Geografía e Informática (INEGI), en la Encuesta Nacional de Ingresos y Gastos para los Hogares 2010. De acuerdo con dichas mediciones, entre 2008 y 2010 se registró una caída del ingreso promedio por hogares de $12,3 \%$ a nivel nacional y de $8,11 \%$ en el Distrito Federal (Evalúa DF, 2010). Y según el cálculo del Índice de Desarrollo Social $^{3}$, el número de personas en grados bajos y muy bajos alcanza a 51,2\% del total (4,5 millones de personas); y en términos de la ciudad construida, se manifiesta en el $43 \%$ de las manzanas urbanas del Distrito Federal (cuadro 1).

pobres, resultado de los procesos de segregación residencial desde los ańos ochenta en América Latina, donde se concentra la población con graves privaciones materiales, muy pocas esperanzas de inserción estable en la estructura productiva y escasa formación de redes de reciprocidad, que son expulsados hacia la periferia. Véase también Kaztman y Retamoso (2005, p. 136).

2 Estas cifras representan la suma total de la población que se encuentra en pobreza alimentaria, pobreza patrimonial y pobreza de capacidades.

3 Se define "desarrollo social" como un proceso de mejoramiento e igualación de las condiciones generales de bienestar de la población, que permite una mejor calidad de vida. En este caso se calculó según el método de las necesidades básicas insatisfechas, con las siguientes dimensiones: calidad y espacio disponible en la vivienda, acceso a electricidad, bienes durables, adecuación sanitaria, acceso a seguridad social y rezago educativo (Evalúa DF, 2011). 
CUADRo I | Distrito Federal. Grado de desarrollo por población y manzanas

\begin{tabular}{|l|c|c|c|c|}
\hline \multicolumn{1}{|c|}{ GRADO } & POBLACIÓN & \% & MANZANAS & \% \\
\hline Alto & 2.152 .593 & 24,32 & 19.535 & 32,01 \\
\hline Medio & 1.938 .016 & 21,90 & 12.831 & 21,02 \\
\hline Bajo & 2.522 .598 & 28,50 & 13.747 & 22,52 \\
\hline Muy bajo & 2.017 .590 & 22,79 & 12.516 & 20,51 \\
\hline Sin datos & 220.242 & 2,49 & 2.405 & 3,94 \\
\hline Total & 8.851 .039 & 100 & 61.034 & 100 \\
\hline
\end{tabular}

FUENTE ÍNDice DE DESARRollo SOCial, 20 Io (EVALÚa DF). EN HTTP://WWW.EVAlua.DF.gob.MX/ MEDICION-UNIDADES-TERRITORIALES-2OIO.PHP

Algunas de las delegaciones periféricas del Distrito Federal presentaron un muy bajo nivel de desarrollo social, que estaba por abajo del 25\%. Dicho de otra manera, dichas delegaciones son las que presentan los mayores porcentajes de población en condiciones de pobreza y, por lo tanto, con las peores condiciones en vivienda, salud y educación.

Si analizamos la distribución espacial de los grupos pobres, su patrón territorial nos muestra varios tipos característicos. En primer lugar identificamos los barrios o colonias pobres, que se localizan sobre todo en el norte del DF, en el oriente y en el sur, en delegaciones que presentan desarrollos urbanos periféricos y zonas de topografía accidentada, como Gustavo A. Madero, Iztapalapa o Magdalena Contreras. En segundo término sobresalen franjas de pobreza que se han desarrollado a lo largo de ejes de comunicación en zonas de marcadas carencias; es el caso del sur de la delegación de Xochimilco y su conexión con la delegación de Tláhuac. En tercer lugar se observan manchones urbanos en la periferia más lejana, como es el caso de la Delegación de Milpa Alta, y Tlalpan. Y finalmente, enclaves urbanos de pobreza, que se refieren a zonas de pobreza de menores dimensiones que se pueden ubicar en localizaciones urbanas centrales y suburbios interiores que se han mantenido por muchos años en esas condiciones (figura 1).

Es indiscutible que estas diferentes localizaciones señalan sitios donde se acumulan y multiplican las desventajas, tanto en forma individual como colectiva; y la mayoría de tales sitios tiene una localización periférica en relación con toda la ciudad. A continuación presentamos el análisis de algunos de estos barrios, para contrastar sus principales rasgos desde la perspectiva de su localización y su condición de pobreza. 
FIGURA I | Índice de desarrollo social por manzana, 2010

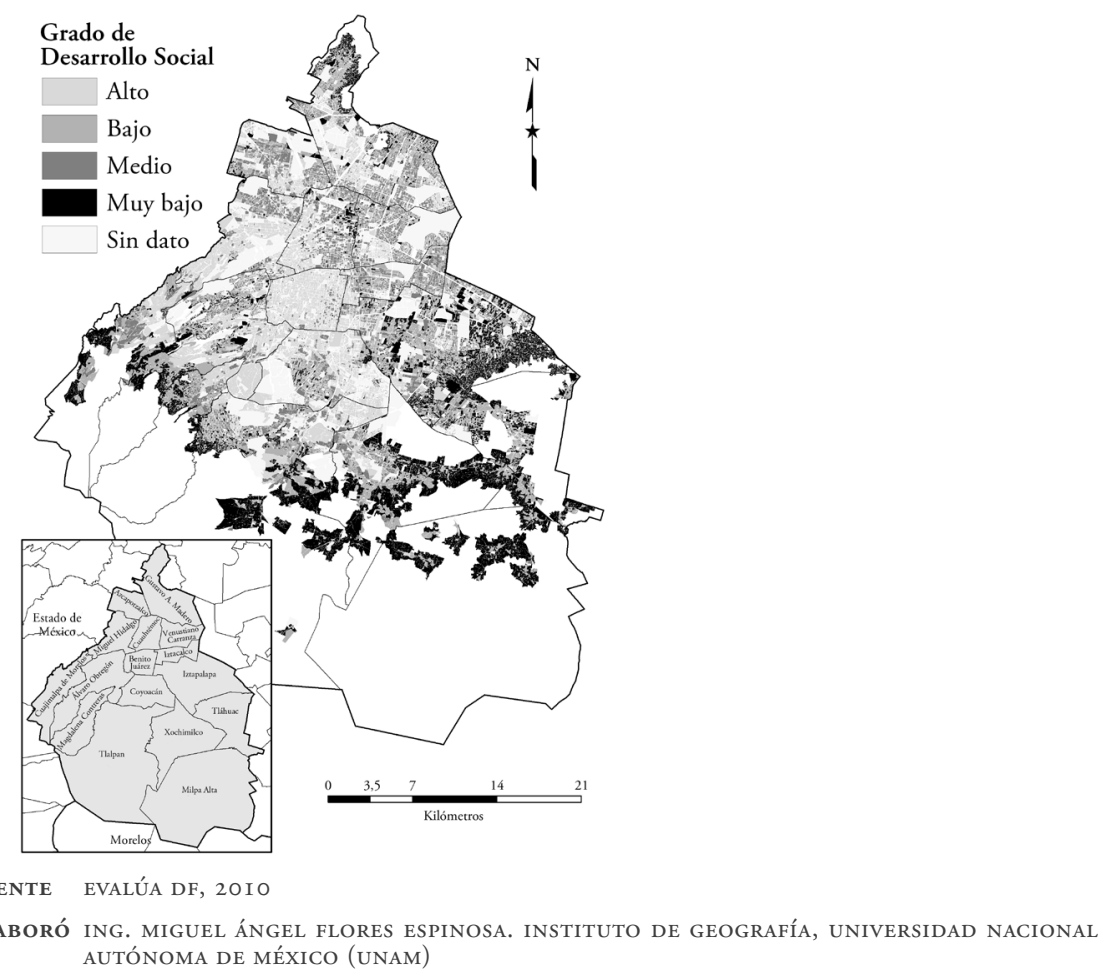

\section{La aplicación de encuestas en siete colonias pobres. Aspectos metodológicos}

En esta sección se presentan los resultados de 329 encuestas aplicadas en siete colonias, todas localizadas dentro de la Zona Metropolitana de la Ciudad de México (zMcM) (cuadro 2), que fueron seleccionadas bajo los siguientes dos criterios: el primero fue por sus características socioeconómicas, determinadas por Evalúa DF (2010), según el cual en 2010 eran colonias que registraron muy bajo grado de desarrollo social. El municipio de Chimalhuacán se seleccionó porque en la evaluación de CONEVAl (2010) tenía uno de los más altos índices de rezago social.

Como segundo criterio, se eligió a las colonias según su localización, y sobre esa base se las clasificó como suburbio interior, periferia urbana y periferia rural. Para el caso del suburbio interior, se hace referencia a la delegación Iztapalapa, al oriente del Distrito Federal, en la que se eligieron dos colonias consolidadas: Desarrollo Urbano Quetzalcóatl y San Juan Buenavista. Como periferia urbana en el Estado de México, se eligió al municipio de Chimalhuacán, del cual se seleccionaron tres colonias sin consolidar en la orilla de la mancha urbana: Tlatelxochitenco, Tepalcates y 4 de Febrero. Y con respecto a la periferia rural, se eligió la delegación Milpa Alta, ubicada al extremo sureste del Distrito Federal y con un predominio de áreas rurales, en la que se seleccionaron las colonias de San Juan y Nustla (figura 2). 
CUADRO 2 Distribución de encuestas por delegación/municipio y colonia

\begin{tabular}{|c|c|c|c|c|}
\hline DELEGACIÓN/MUNICIPIO & $\begin{array}{l}\text { NÚMERO DE } \\
\text { ENCUESTAS }\end{array}$ & PERSONAS & $\begin{array}{c}\text { ÍNDICE DE } \\
\text { DESARROLLO } \\
\text { SOCIAL } \\
\end{array}$ & $\begin{array}{l}\text { CLASIFICACIÓN } \\
\text { POR } \\
\text { LOCALIZACIÓN }\end{array}$ \\
\hline \multicolumn{5}{|l|}{ Iztapalapa } \\
\hline Desarrollo Urbano Quetzalcoatl & 62 & 302 & Muy bajo & \multirow{2}{*}{ Suburbio urbano } \\
\hline San José Buenavista & 59 & 278 & Muy bajo & \\
\hline \multicolumn{5}{|l|}{ Milpa Alta } \\
\hline San Juan & 44 & 189 & Muy bajo & \multirow{2}{*}{ Periferia rural } \\
\hline Nushtla & 45 & 187 & Muy bajo & \\
\hline \multicolumn{5}{|l|}{ Chimalhuacán } \\
\hline Tlatelxochitenco & 31 & 189 & Muy bajo & \multirow{3}{*}{ Periferia urbana } \\
\hline Tepalcates & 49 & 158 & Muy bajo & \\
\hline 4 de Febrero & 40 & 189 & Muy bajo & \\
\hline Total & 329 & 1.479 & & \\
\hline
\end{tabular}

FIGURA 2 Localización de colonias/municipio

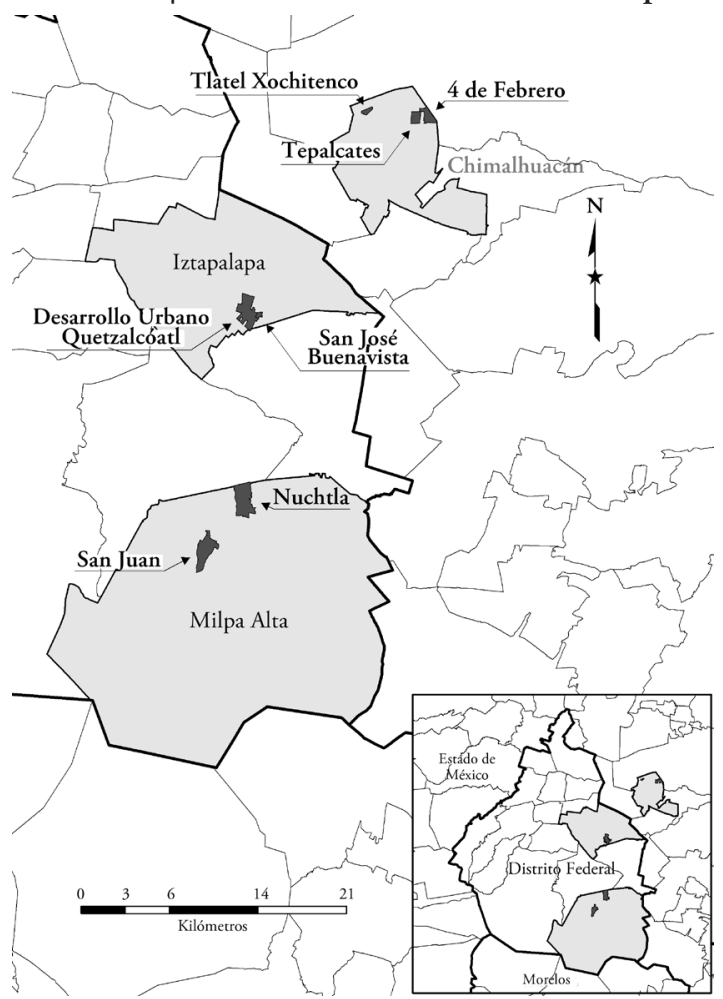

FUENTE INEGI, 2OIO

ELABORÓ ING. MIGUEL ÁNGEL FLORES ESPINOSA. INSTITUTO DE GEOGRAFÍA, UNIVERSIDAD NACIONAL AUTÓNOMA DE MÉXICO (UNAM) 
El propósito del estudio en esta fase fue colectar información de la población asentada en estas colonias para identificar la acumulación de desventajas que agravan la intensidad de pobreza en la que viven, y establecer diferencias según su localización periférica o de suburbio interior. La acumulación de desventajas se explica a través de tres perspectivas. La primera se refiere a la medición de necesidades básicas insatisfechas (NBI) que, de acuerdo con Boltvinik (1997) es "la integración de satisfactores de las necesidades básicas de una persona o de un hogar" (p. 396); estos satisfactores básicos son ingresos, acceso a los servicios urbanos y sociales, patrimonio básico, niveles educativos y capacidad del endeudamiento del hogar. La segunda perspectiva engloba las características laborales, como tipo de ocupación y contratación, así como niveles de ingreso que permiten o no la adquisición o mejoramiento de sus NBI. Y la tercera se relaciona con las estrategias de sobrevivencia que desarrollan los pobres para atenuar de forma parcial o temporal su condición.

La aplicación de encuestas permitió examinar el grado de acceso a satisfactores básicos a través del método de NBI, tomado del método de medición integral de la pobreza (MMIP) construido por Boltvinik (1997, p. 394), para lo cual se utilizaron los procedimientos necesarios para la determinación de los índices e indicadores compuestos por NBI, que incluyen: i) la calidad de la vivienda, es decir, la calidad de los materiales con los que está construida la vivienda y los espacios disponibles de la misma, cuya ocupación está en función del número de personas que la ocupa; ii) los servicios urbanos de la vivienda, con variables como agua, energía eléctrica y servicio de recolección de basura; iii) servicios sociales, que se forma por la suma de las variables de educación y salud (cuadro 3).

De acuerdo con el método NBI, a cada variable de cada dimensión se le asigna un valor, el cual representa su situación; es decir, mientras mayor sea su valor, mejor situación representará. Esos valores pueden oscilar entre 0 , como el valor que indica la peor situación; 2 que implica una situación medianamente adecuada; y 3 que apunta a la mejor situación. Por lo regular, el valor que representa la mejor situación del estado de las dimensiones, se fija como la norma idónea de cada conjunto de variables que forman una dimensión. Posteriormente, se realiza la suma de los valores del conjunto de variables que componen cada dimensión y se divide entre el valor que representa la situación idónea. Finalmente, se suman los resultados de cada dimensión y se divide entre el número total de dimensiones, con lo que se establece el índice global de necesidades básicas insatisfechas del MMIP (cuadro 3).

Los resultados de las encuestas indican que la pobreza se estratifica en varios niveles, ordenados de la situación menos grave a la más grave, en las siguientes categorías: no pobres, pobres moderados, pobreza extrema y pobres indigentes (Boltvinik, 1997, p. 396). 
CUADro 3 | Metodología de medición de la pobreza por necesidades básicas insatisfechas

\begin{tabular}{|c|c|c|c|c|c|}
\hline \multicolumn{2}{|c|}{ ELEMENTOS } & COMPOSICIÓN & VALOR $(v)$ & NORMA & $\begin{array}{l}\text { INDICADOR } \\
\text { CONSOLIDADO }\end{array}$ \\
\hline \multicolumn{6}{|c|}{ Consolidación de la vivienda $(\mathrm{CnVv})$} \\
\hline \multirow{15}{*}{$\begin{array}{l}\text { Estructura } \\
\text { de la vivien- } \\
\text { da (Et) }\end{array}$} & \multirow{3}{*}{ Pisos (Ps) } & Tierra firme & 0 & \multirow{3}{*}{2} & \multirow{23}{*}{$\mathrm{CnVv}=\mathrm{Et}+\mathrm{EsDs} / 2$} \\
\hline & & Cemento & 1 & & \\
\hline & & Madera, mosaico, etc. & 2 & & \\
\hline & \multirow{3}{*}{ Muros (Ms) } & Lámina de cartón o madera & 0 & \multirow{3}{*}{2} & \\
\hline & & Piedra o adobe & 1 & & \\
\hline & & Cemento, tabicón o tabique & 2 & & \\
\hline & \multirow{3}{*}{ Techos (Ts) } & Cartón y madera & 0 & \multirow{3}{*}{2} & \\
\hline & & Lámina de asbesto o metálica & 1 & & \\
\hline & & Losa de concreto, tabique o teja & 2 & & \\
\hline & \multirow{3}{*}{$\begin{array}{l}\text { Recubri- } \\
\text { miento } \\
\text { de muros } \\
\text { (RMs) }\end{array}$} & Sin acabados & 0 & \multirow{3}{*}{2} & \\
\hline & & Cal o pintura sobre tabique & 1 & & \\
\hline & & Repellado, revoque, yeso & 2 & & \\
\hline & \multirow{3}{*}{$\begin{array}{l}\text { Ventilación- } \\
\text { Iluminación } \\
\text { (Vln) }\end{array}$} & Ningún cuarto tiene ventanas & 0 & \multirow{3}{*}{2} & \\
\hline & & $\begin{array}{l}\text { Solo algunos cuartos tienen } \\
\text { ventanas }\end{array}$ & 1 & & \\
\hline & & $\begin{array}{l}\text { Todos los cuartos tienen } \\
\text { ventanas }\end{array}$ & 2 & & \\
\hline \multirow{8}{*}{$\begin{array}{l}\text { Espacios } \\
\text { disponibles } \\
\text { (EsDs) }\end{array}$} & \multirow{4}{*}{ Bańos (Bñ) } & No tiene & 0 & \multirow{4}{*}{3} & \\
\hline & & Afuera compartido & 1 & & \\
\hline & & $\begin{array}{l}\text { Afuera exclusivo o adentro } \\
\text { compartido }\end{array}$ & 2 & & \\
\hline & & Adentro exclusivo & 3 & & \\
\hline & \multirow{3}{*}{ Cocina $(\mathrm{Ca})$} & No tiene & 0 & \multirow{3}{*}{2} & \\
\hline & & $\begin{array}{l}\text { Con cocina que también se usa } \\
\text { para dormir }\end{array}$ & 1 & & \\
\hline & & $\begin{array}{l}\text { Con cocina que no se usa para } \\
\text { dormir }\end{array}$ & 2 & & \\
\hline & $\begin{array}{l}\text { Cuartos } \\
\text { por persona } \\
(\mathrm{Cpa})\end{array}$ & $\begin{array}{l}\text { Inversa a la fórmula de hacina- } \\
\text { miento (cuartos/persona) }\end{array}$ & N/A & 0,5 & \\
\hline Servicios de & vivienda ( $\mathrm{S}$ & $\left(V_{v}\right)$ & & & \\
\hline
\end{tabular}


(continuación)

\begin{tabular}{|c|c|c|c|c|c|}
\hline \multicolumn{2}{|c|}{ ELEMENTOS } & СОMPOSICIÓN & VALOR (v) & NORMA & INDICADOR \\
\hline \multirow{8}{*}{ Agua (Ag) } & \multirow{3}{*}{$\begin{array}{l}\text { Forma de } \\
\text { abasto de } \\
\text { agua (FAb) }\end{array}$} & Llave pública, pipas y otros & 1 & \multirow{3}{*}{3} & \multirow{20}{*}{$\mathrm{ScVv}=\mathrm{Ag}+\mathrm{SrUr} / 2$} \\
\hline & & Entubada fuera de la vivienda & 2 & & \\
\hline & & Entubada dentro de la vivienda & 3 & & \\
\hline & \begin{tabular}{|l|} 
Frecuencia \\
$($ Frc $)$
\end{tabular} & 16 hrs. al día x 7 días & N/A & $\begin{array}{c}112 \mathrm{hrs} . \\
\text { por semana }\end{array}$ & \\
\hline & \multirow{4}{*}{$\begin{array}{l}\text { Calidad } \\
\text { (Cd) }\end{array}$} & Con tres problemas & 0 & \multirow{4}{*}{ 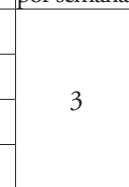 } & \\
\hline & & Con dos problemas & 1 & & \\
\hline & & Con un problema & 2 & & \\
\hline & & Limpia & 3 & & \\
\hline \multirow{12}{*}{$\begin{array}{l}\text { Servicios } \\
\text { urbanos } \\
\text { (SrUr) }\end{array}$} & \multirow{2}{*}{$\begin{array}{l}\text { Drenaje } \\
(\mathrm{De})\end{array}$} & $\begin{array}{l}\text { En la calle, en un caño o barran- } \\
\text { ca u otra situación }\end{array}$ & 0 & \multirow{2}{*}{1} & \\
\hline & & $\begin{array}{l}\text { En fosa séptica o en drenaje de } \\
\text { la calle }\end{array}$ & 1 & & \\
\hline & \multirow{4}{*}{$\begin{array}{l}\text { Excusado } \\
(\mathrm{Ec})\end{array}$} & $\mathrm{Al}$ aire libre & 0 & \multirow{4}{*}{3} & \\
\hline & & Hoyo negro o letrina & 1 & & \\
\hline & & Excusado sin agua corriente & 2 & & \\
\hline & & Excusado con agua corriente & 3 & & \\
\hline & \multirow{3}{*}{ Basura (Ba) } & Cualquier otra & 0 & \multirow{3}{*}{2} & \\
\hline & & Depósito fijo & 1 & & \\
\hline & & La recoge el camión & 2 & & \\
\hline & \multirow{3}{*}{$\begin{array}{l}\text { Electricidad } \\
\text { (Elt) }\end{array}$} & No tiene & 0 & \multirow{3}{*}{2} & \\
\hline & & Tiene sin medidor & 1 & & \\
\hline & & Tiene con medidor & 2 & & \\
\hline \multicolumn{6}{|c|}{ Servicios sociales (ScSoc) } \\
\hline \multirow{3}{*}{$\begin{array}{l}\text { Educación } \\
\text { (Ed) }\end{array}$} & $\begin{array}{l}\text { Integrantes } \\
\text { de la familia } \\
\text { (Ifm) }\end{array}$ & \multirow{3}{*}{\multicolumn{2}{|c|}{$\begin{array}{l}\text { Se aplicará la norma educativa por cada } \\
\text { integrante mayor a } 7 \text { años de edad. Relación } \\
\text { edad con grados aprobados en la escuela. }\end{array}$}} & \multirow{3}{*}{$\begin{array}{l}\text { Relación } \\
\text { edad con } \\
\text { grados en } \\
\text { la escuela }\end{array}$} & \multirow{3}{*}{$\begin{array}{l}\text { Ed por Ifm=Acur/ } \\
\text { Ned }\end{array}$} \\
\hline & $\begin{array}{l}\text { Años cursa- } \\
\text { dos (Acur) }\end{array}$ & & & & \\
\hline & \begin{tabular}{|l|}
$\begin{array}{l}\text { Norma } \\
\text { educativa } \\
\text { (Ned) }\end{array}$ \\
\end{tabular} & & & & \\
\hline \multirow{4}{*}{ Salud (Sd) } & \multirow{4}{*}{$\begin{array}{l}\text { Atención a } \\
\text { la salud y } \\
\text { seguridad } \\
\text { social }(\mathrm{SdSs})\end{array}$} & $\begin{array}{l}\text { No tiene derecho a ningún } \\
\text { servicio de salud }\end{array}$ & 0 & \multirow{4}{*}{2} & \multirow{4}{*}{$\mathrm{Sd}=\mathrm{VSd} \mathrm{Ss} / 2$} \\
\hline & & Otro servicio médico & 1 & & \\
\hline & & IMSS o ISSSTE & 2 & & \\
\hline & & Empresa o sindicato & 3 & & \\
\hline
\end{tabular}

FUENTE ELABORACión PROPIA A PARTIR DE LOS RESUltados DE LAS ENCUESTAS APLiCADAS A CADA COLONIA

ELABORó ISABELA ROJAS VILLAMAR 


\section{Los niveles de pobreza por necesidades básicas insatisfechas}

De acuerdo a los resultados del índice global por necesidades básicas insatisfechas, la mayor proporción de hogares se ubicó en el estrato de los pobres indigentes, como se observa en el cuadro 4; seis de la siete colonias indican una fuerte intensidad de la pobreza en la que está sumida la población.

CUADRo 4 | Índice global de la pobreza por estrato

\begin{tabular}{|c|c|c|}
\hline DELEGACIÓN/MUNICIPIO & ÍNDICE GLOBAL & ESTRATOS \\
\hline \multicolumn{3}{|l|}{ Iztapalapa } \\
\hline - Desarrollo Urbano Quetzalcoatl & 0,4 & Pobres indigentes \\
\hline - San José Buenavista & 0,36 & Pobres extremos \\
\hline \multicolumn{3}{|l|}{ Milpa Alta } \\
\hline - San Juan & 0,39 & Pobres indigentes \\
\hline - Nushtla & 0,42 & Pobres indigentes \\
\hline \multicolumn{3}{|l|}{ Chimalhuacán } \\
\hline - 4 de Febrero & 0,32 & Pobres indigentes \\
\hline - Tepalcates & 0,33 & Pobres indigentes \\
\hline - Tlatelxochitenco & 0,32 & Pobres indigentes \\
\hline
\end{tabular}

Sin embargo, si analizamos de forma desglosada las NBI -es decir, por cada uno de los grandes grupos: espacios disponibles, servicios urbanos, servicios sociales, agua y calidad de la vivienda-, se identifica una fuerte diferencia en el comportamiento de los indicadores. Esto es, existe una marcada desigualdad entre todas las colonias en los valores de una o varias variables, que indican altos o bajos niveles de pobreza.

Ante esta falta de correspondencia en los valores, a continuación se explicarán los resultados del método de medición de NBI aplicado a cada una de las variables en las siete colonias.

En el cuadro 5A se presenta el primer grupo de indicadores, de los cuales el indicador de espacios disponibles y el de servicios sociales como educación y salud, registran condiciones de pobreza y dan lugar al mayor número de valores de indigencia para las colonias.

CUADRO 5A Indicador de pobreza por necesidades básicas insatisfechas

\begin{tabular}{|c|c|c|c|c|c|c|}
\hline \multirow[t]{2}{*}{ DELEGACIÓN/MUNICIPIO } & \multicolumn{2}{|c|}{$\begin{array}{c}\text { ESPACIOS } \\
\text { DISPONIBLES }\end{array}$} & \multicolumn{2}{|c|}{$\begin{array}{c}\text { SERVICIOS } \\
\text { URBANOS }\end{array}$} & \multicolumn{2}{|c|}{ SERVICIOS SOCIALES } \\
\hline & VALOR & ESTRATO & VALOR & ESTRATO & VALOR & ESTRATO \\
\hline \multicolumn{7}{|l|}{ Iztapalapa } \\
\hline - Desarrollo Urbano Quetzalcoatl & 0,25 & Indigente & 0,88 & NBS & 0,56 & Pobres extremos \\
\hline - San José Buenavista & 0,39 & Indigente & 0,9 & NBS & 0,9 & Pobres indigentes \\
\hline \multicolumn{7}{|l|}{ Milpa Alta } \\
\hline - San Juan & 0,34 & Indigente & 0,88 & NBS & 0,55 & Pobres extremos \\
\hline - Nushtla & 0,4 & Indigente & 0,76 & NBS & 0,47 & Pobres indigentes \\
\hline \multicolumn{7}{|l|}{ Chimalhuacán } \\
\hline - 4 de Febrero & 0,49 & Indigente & 0,89 & NBS & 0,55 & Pobres extremos \\
\hline - Tepalcates & 0,35 & Indigente & 0,94 & NBS & 0,53 & Pobres extremos \\
\hline - Tlatexochitenco & 0,24 & Indigente & 0,93 & NBS & 0,63 & Pobres extremos \\
\hline
\end{tabular}

FUENTE ELABORACIÓN PROPIA A PARTIR DE LOS RESULTADOS DE LAS ENCUESTAS APLICADAS A CADA COLONIA 
De acuerdo con los resultados del Cuadro 5A, podemos señalar lo siguiente:

a. Espacios disponibles ${ }^{4}$. Es quizá el indicador que presenta una marcada condición precaria y cuya similitud de valores entre todas las colonias evidenció un alto número de integrantes por vivienda, o una sobreocupación de ellas. Lo anterior se explica por dos constantes: la primera es que muchas viviendas han sido por mucho tiempo construcciones inconclusas, y cuentan con habitaciones inhabitables, sobre todo las que se quedaron a media construcción en el segundo piso; y la segunda es que en una vivienda se albergaron más de dos familias, situación en que se encontraba el $14 \%$ de las familias con respecto al total de las viviendas de las siete colonias.

b. Los servicios sociales de salud y educación. Fue el indicador que ocupó el segundo lugar en nivel de precariedad. El nivel de escolaridad de todas las colonias presentó un promedio de $46 \%$ de la población con primaria incompleta, con solo tercer grado cursado. Dos excepciones fueron San Juan en Milpa Alta y Tlatelxochitenco, cuyos ocupantes cursaron la primaria completa. El indicador Educación presentó los valores más bajos, entre la indigencia y la pobreza extrema. En cuanto a Salud, el valor que predominó fue el de pobreza extrema. Este indicador mostró cierta uniformidad, ya que el $72 \%$ de la población de las siete colonias señaló tener algún tipo de alternativa para resolver su estado de salud; por ejemplo, el $35 \%$ de la población encuestada reportó acudir a las farmacias con consultorio médico anexo.

c. Los servicios urbanos. Esta variable mostró valores registrados predominantemente en el estrato de Necesidades Básicas Satisfechas. Con referencia al segundo grupo de indicadores, si se observa de forma horizontal el cuadro 5B, se identifica una calidad en el suministro de los servicios muy desigual, desde índices de indigencia hasta niveles de pobreza moderada.

CUADRO 5 В Indicador de pobreza por necesidades básicas insatisfechas

\begin{tabular}{|c|c|c|c|c|}
\hline \multirow{2}{*}{ DELEGACIÓN/MUNICIPIO } & \multicolumn{2}{|r|}{ AGUA } & \multicolumn{2}{|c|}{ CALIDAD DE LA VIVIENDA } \\
\hline & VALOR & ESTRATO & VALOR & ESTRATO \\
\hline \multicolumn{5}{|l|}{ Iztapalapa } \\
\hline - Desarrollo Urbano Quetzalcoatl & 0,18 & Indigente & 0,88 & Pobreza moderada \\
\hline - San José Buenavista & 0,49 & Indigente & 0,79 & Pobreza moderada \\
\hline \multicolumn{5}{|l|}{ Milpa Alta } \\
\hline - San Juan & 0,48 & Indigente & 0,75 & Pobreza moderada \\
\hline - Nushtla & 0,58 & Pobreza extrema & 0,63 & Pobreza extrema \\
\hline \multicolumn{5}{|l|}{ Chimalhuacán } \\
\hline - 4 de Febrero & 0,89 & NBS & 0,52 & Pobreza extrema \\
\hline - Tepalcates & 0,87 & Pobreza moderada & 0,66 & Pobreza extrema \\
\hline - Tlatexochitenco & 0,89 & NBS & 0,67 & Pobreza extrema \\
\hline
\end{tabular}


d. Agua. El indicador Agua fue el más desigual entre todas las colonias, ya que sus valores oscilaron entre todos los estratos, desde la indigencia hasta las necesidades básicas satisfechas.

e. Calidad de la vivienda. Siendo la vivienda aquella unidad donde se desarrolla la vida privada de una familia (Boltvinik, 2010, p. 122), su calidad es de primera importancia, puesto que debe garantizar a sus habitantes estabilidad y protección. El indicador Calidad de la Vivienda oscila en las siete colonias entre la pobreza extrema y la pobreza moderada. La calidad de las viviendas de Iztapalapa se encuentra en el rango de pobreza moderada. En esta delegación fue más común localizar viviendas consolidadas en cuanto a sus materiales, es decir, con las paredes y el techo de concreto, muchas de ellas con habitaciones inconclusas y ubicadas en zonas de riesgo; al mismo tiempo, se identificaron algunas viviendas que reflejaron estabilidad estructural y el consiguiente progreso socioeconómico familiar, representados por grandes construcciones en forma vertical o hasta con acabados de lujo. En cambio, las viviendas que se ubicaron en el estrato de pobreza extrema evidencian niveles muy bajos de consolidación y de inversión para mejorar su estructura, sobre todo porque están construidas con materiales frágiles, como cartón, madera o lámina, las cuales son más propensas a derrumbarse y deteriorase ante las inclemencias del clima.

\section{Niveles de ingreso y ocupación}

Los ingresos dependen directamente del tipo de ocupación y de las condiciones de contratación del trabajador, de lo cual también depende que la pobreza se prolongue a largo plazo. Un nivel de ocupación precario contribuye a que los trabajadores sean pobres y los imposibilita de superar el nivel y condición de pobreza en el que se encuentran. Los trabajadores que se dedican a ocupaciones no calificadas tienden a permanecer en la misma condición de pobreza. Y la combinación de todo lo anterior se puede traducir en una rigidez en la movilidad laboral (Bayón, 174, p. 2009).

A continuación nos referimos al nivel de ingresos de la población encuestada, a su capacidad de compra y al tipo de ocupaciones que desempeña.

a. Ingresos. De acuerdo con los resultados de la encuesta, la mayor proporción de población ocupada encuestada $(43 \%)$ obtiene en promedio entre uno y dos salarios mínimos (cabe mencionar que en algunas colonias este porcentaje está por arriba del 50\%); si al porcentaje anterior le agregamos la población ocupada que obtiene menos de un salario mínimo, tenemos que, en promedio, un total de $58 \%$ de esa población gana un salario muy bajo. Por otra parte, no se puede dejar de mencionar que un porcentaje importante de la población ocupada gana un salario de entre dos y tres salarios mínimos, lo cual parece indicar que una tercera parte de la población está por encima del nivel de pobreza extrema únicamente desde el punto de vista del ingreso (cuadro 6). 
CUADro 6 | Niveles de ingreso por colonia. Salarios mínimos (sm) (en porcentajes)

\begin{tabular}{|l|c|c|c|c|c|}
\hline \multicolumn{1}{|c|}{ DELEGACIÓN/MUNICIPIO } & $\begin{array}{c}\text { MENOS DE } \\
\text { I SM }\end{array}$ & $\begin{array}{c}\text { DE I A 2 } \\
\text { SM }\end{array}$ & $\begin{array}{c}\text { DE 2 A 3 } \\
\text { SM }\end{array}$ & $\begin{array}{c}\text { DE 3 A 5 } \\
\text { SM }\end{array}$ & $\begin{array}{c}\text { MÁs DE 5 } \\
\text { SM }\end{array}$ \\
\hline Iztapalapa \\
\hline - Desarrollo Urbano Quetzalcoatl & 4,9 & 37,3 & 45,1 & 11,8 & 1,0 \\
\hline - San José Buenavista & 31,1 & 39,2 & 21,6 & 6,8 & 1,4 \\
\hline Milpa Alta & 12,4 & 53,6 & 29,4 & 4,6 & 0,0 \\
\hline - San Juan & 13,6 & 53,6 & 29,4 & 4,6 & 0,0 \\
\hline - Nushtla & \multicolumn{5}{|l|}{} \\
\hline Chimalhuacán & 26,5 & 32,5 & 38,6 & 2,4 & 0,0 \\
\hline - 4 de Febrero & 6,9 & 37,9 & 41,4 & 13,8 & 0,0 \\
\hline - Tepalcates & 9,4 & 43,8 & 40,6 & 3,1 & 3,1 \\
\hline - Tlatexochitenco & 15 & 42,5 & 35,2 & 6,5 & 0,8 \\
\hline Promedio
\end{tabular}

FUENTE ELABORACIÓN PROPIA A PARTIR DE LOS RESULTADOS DE LAS ENCUESTAS APLICADAS A CADA COLONIA

Desde la perspectiva de las colonias, se aprecia que en la mayoría de ellas, cuatro en lo particular, más del $60 \%$ de la población ocupada gana menos de dos salarios mínimos, con lo cual estas colonias se colocan por debajo de la línea de pobreza. Lo importante en este caso es que los niveles de ingreso son muy bajos para comprar la canasta básica integral (CBI $)^{5}$; dado el costo de la $\mathrm{CBI}^{6}$, por un lado, y el salario mínimo mensual existente en el Distrito Federal, por otro, se tiene que este último solo alcanzaba para adquirir el $80 \%$ de la CBI el ańo 2013.

Para el caso del presente estudio, se hizo la correlación de los salarios mínimos y la capacidad de compra de la $\mathrm{CBI}^{7}$ para cada asentamiento, encontrándose que las dos situaciones más desfavorables son las siguientes: primero, en los dos asentamientos de Iztapalapa, entre el $54 \%$ y el $70 \%$ de la población únicamente alcanza a cubrir el 60\% de la СBI; segundo, en los dos asentamientos de Milpa Alta, el 80\% de la población únicamente alcanza a cubrir el $60 \%$ de la CBI. Por otro lado, los asentamientos en Chimalhuacán mostraron una mejor situación, ya que más del $50 \%$ de su población sí cubre la CBI (cuadro 7).

5 La canasta básica integral (СBI) se refiere a la suma del precio per cápita mensual de la canasta básica alimentaria y del precio per cápita mensual de la canasta básica de requerimientos mínimos en zonas urbanas.

6 El costo de la CBI para el año 2013 fue de 2.415,45 pesos mensuales per cápita para zonas urbanas; el salario mínimo para el año 2013 fue de $1.942,80$ pesos mensuales y de 64,76 pesos diarios.

7 La medición de la capacidad de compra de la canasta básica integral consistió en sumar los ingresos percibidos al mes por familia, y el total se dividió entre los integrantes de la familia. 
CUADRO 7 | Capacidad de compra de la canasta básica integral (en porcentajes)

\begin{tabular}{|l|c|c|c|c|}
\hline \multirow{2}{*}{ DELEGACIÓN/MUNICIPIO } & \multicolumn{4}{|c|}{ CAPACIDAD DE COMPRA DE LA CANASTA BÁsICA INTEGRAL } \\
\cline { 2 - 5 } & $\mathbf{0 - 3 0}$ & $\mathbf{3} \mathbf{I - 6 0}$ & $\mathbf{6 I - 9 0}$ & MÁs DE 90 \\
\hline Iztapalapa & \multicolumn{5}{|l|}{} \\
\hline - Desarrollo Urbano Quetzalcoatl & 20,54 & 33,33 & 19,19 & 26,94 \\
\hline - San José Buenavista & 33,45 & 37,41 & 16,91 & 12,23 \\
\hline Milpa Alta & 43,39 & 37,57 & 7,94 & 11,11 \\
\hline - San Juan & 43,32 & 42,78 & 9,09 & 4,81 \\
\hline - Nushtla & \multicolumn{5}{|c|}{} \\
\hline Chimalhuacán & 16,93 & 33,86 & 20,63 & 28,57 \\
\hline - - d de Febrero & 6,74 & 40,93 & 23,32 & 29,02 \\
\hline - Tlatelxochitenco & 12,90 & 23,23 & 37,42 & 26,45 \\
\hline - Tepalcates &
\end{tabular}

FUENTE ELABORACIÓN PROPIA A PARTIR DE LOS RESULTADOS DE LAS ENCUESTAS APLICADAS A CADA COLONIA

b. Tipo de ocupación. Los niveles de ocupación laboral se presentan en el cuadro 8, en el cual se observa que oscilan desde las labores menos calificadas, como actividades de apoyo y algún tipo de oficio, hasta aquellas con algún nivel de calificación, como en el caso de los trabajadores en el sector servicios o los profesionistas. Es importante resaltar que muchas de estas ocupaciones se desarrollan en el ámbito de la informalidad. De la población encuestada, solo el 38\% declaró estar ocupada al momento de la entrevista, lo cual da cuenta indirectamente de un alto nivel de desempleo. El cuadro 8 ordena las cuatro ocupaciones con los porcentajes más altos: i) Comerciantes y Empleados en Ventas, con un 40\%; ii) Operadores de Maquinaria, Ensambladores y Choferes, con 22\%; iii) Trabajadores en Actividades de Apoyo, con 9\%; iv) y en las ocupaciones de más alta calificación, Profesionales y Técnicos, se registró un 10\% de la población ocupada. En estas cuatro categorías se agrupa el $81 \%$ de toda la población ocupada. 


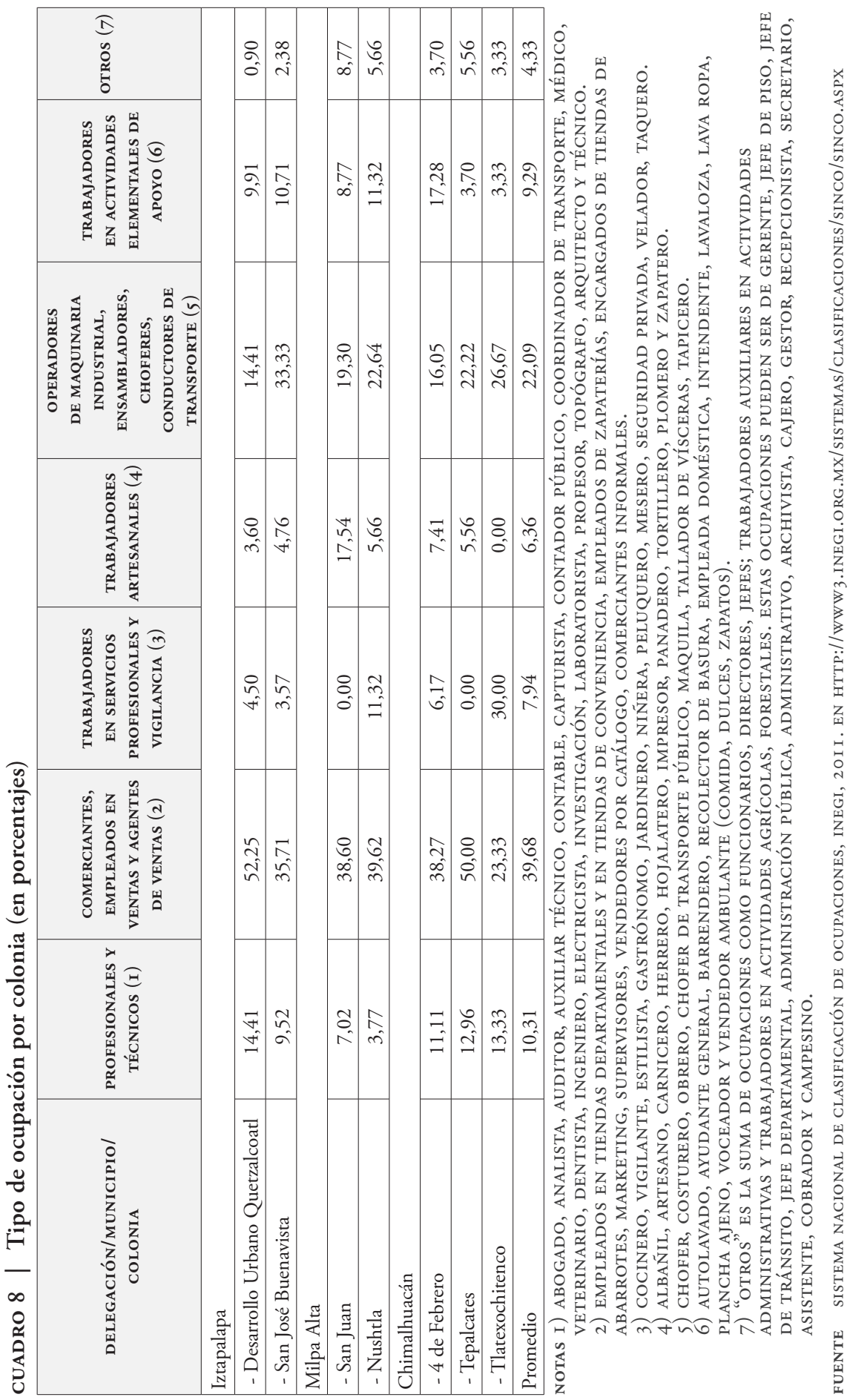




\section{Inseguridad laboral}

La inseguridad laboral se refiere no solo a la incertidumbre que experimentan los trabajadores por permanecer en el empleo, conseguir ingresos a través de trabajos parciales y/o temporales, o vendiendo cualquier cosa a lo largo del día; además, está relacionada con el tipo de contratación laboral, lo cual puede ser un factor que, junto con la precariedad laboral, agudiza la intensidad de la pobreza. En este estudio, la inseguridad laboral se midió a través del tipo de contratación laboral.

En el caso de las colonias encuestadas, se identificaron cuatro tipos de contrataciones (cuadro 9). En orden de importancia, la primera se refiere a la contratación de base, planta o de tiempo indefinido, la cual representó el $44 \%$ de la población ocupada; estos son los trabajadores que cuentan con la mayor seguridad laboral. El segundo tipo incluye a trabajadores que no tienen contrato, con $24 \%$. El tercer tipo comprende a trabajadores temporales o por obra, que registraron un 23\%; estos trabajadores, a pesar de contar con empleo, viven con la incertidumbre de que en cualquier momento ya no se les contrate. Y el cuarto tipo es el autoempleo, que representó el 9\%. Los tres últimos tipos de relaciones laborales sumados representan el $56 \%$ de la población ocupada y se asocian a trabajos eventuales, informales y sin ninguna prestación; es decir, trabajadores que están en una situación altamente vulnerable desde el punto de vista laboral.

El cuadro 9 contiene la relación de las formas de contratación con el tipo de ocupación, y en él se reflejan varios aspectos. Entre estos, que aunque los trabajadores de base o de planta representan el $44 \%$ de la población ocupada, en la encuesta se identificó que, de ese total, solo $24 \%$ tenía seguro médico; solo $21 \%$ tenía seguro de retiro para la jubilación; y solo el 17\% tenía vacaciones con goce de sueldo. En el mismo cuadro se aprecia que estos trabajadores son mayoría en las ocupaciones de profesionistas y en servicios de vigilancia. Los trabajadores que no tienen contrato son mayoría entre los comerciantes y en operadores de maquinaria y choferes. Y los temporales o por obra son mayoría en trabajadores artesanales y en actividades de apoyo y empleados de muy bajo nivel.

Únicamente en las colonias Tepalcates y Tlatelxochitenco (en Chimalhuacán) más del $60 \%$ de la población ocupada presenta una contratación de base, lo cual le da una supuesta seguridad laboral; en el resto de las colonias, la población ocupada vive con un alto grado de incertidumbre laboral, ya que predominan situaciones laborales temporales, sin contrato o de autoempleo. Lo anterior es particularmente más notorio en las colonias de Milpa Alta, donde la contratación de base no rebasa el 20\%. 
CUADRO 9 | Tipo de contratación por ocupación (en porcentajes)

\begin{tabular}{|l|c|c|c|c|}
\hline \multicolumn{1}{|c|}{ TIPO DE CONTRATACIÓN/OCUPACIÓN } & $\begin{array}{c}\text { TEMPORAL } \\
\text { O POR OBRA }\end{array}$ & $\begin{array}{c}\text { DE PLANTA, } \\
\text { BASE O POR } \\
\text { TIEMPO } \\
\text { INDEFINIDO }\end{array}$ & $\begin{array}{c}\text { NO TIENE } \\
\text { CONTRATO }\end{array}$ & $\begin{array}{c}\text { AUTO } \\
\text { EMPLEO }\end{array}$ \\
\hline Profesionales y técnicos & 28,57 & 61,90 & 6,35 & 3,17 \\
\hline $\begin{array}{l}\text { Comerciantes, empleados en ventas y agentes } \\
\text { de ventas }\end{array}$ & 14,43 & 9,28 & 38,14 & 38,14 \\
\hline $\begin{array}{l}\text { Trabajadores en servicios profesionales y } \\
\text { vigilancia }\end{array}$ & 22,58 & 48,39 & 25,81 & 3,23 \\
\hline Trabajadores artesanales & 55,88 & 5,88 & 23,53 & 14,71 \\
\hline $\begin{array}{l}\text { Operadores de maquinaria industrial, ensam- } \\
\text { bladores, choferes, conductores de transporte }\end{array}$ & 31,15 & 35,25 & 26,23 & 7,38 \\
\hline $\begin{array}{l}\text { Trabajadores en actividades elementales de } \\
\text { apoyo }\end{array}$ & 25,26 & 42,11 & 21,58 & 11,05 \\
\hline Otros & 43,75 & 56,25 & 0,00 & 0,00 \\
\hline Promedio & 31,66 & 37,01 & 20,23 & 11,10 \\
\hline
\end{tabular}

\section{Pobreza y cohesión social}

La cohesión social es un indicador que ayuda a medir el nivel de aislamiento de los grupos pobres; es un indicador de organización social para lograr bienes colectivos. Para su obtención, se requiere de una organización social constante que logre elevar el bienestar y la calidad de vida de las familias. De otra manera, la falta y/o ausencia de cohesión social se convierte en una desventaja más, que se acumula y que a su vez agudiza la pobreza.

En este trabajo se consideró la definición de cohesión social que abordan Gordon y Millán (2009), según la cual "es la forma y el fundamento que rigen los vínculos y prácticas sociales que pueden facilitar la puesta en marcha de recursos normativos, como organizativos, culturales para coordinar acciones y atender problemas comunes, sin poner en riesgo la unidad social" (p. 9). Así, para este trabajo, la noción de "cohesión social" se refiere al grado de organización de un grupo de personas que, en conjunto, son capaces de resolver determinadas dificultades y/o problemas que enfrentan para su desarrollo social.

Para medir el grado de cohesión social, se preguntó a quiénes recurren cuando tienen una necesidad que deben resolver de forma inmediata, con las siguientes opciones: familiares, amigos, vecinos. Las necesidades se priorizaron de la siguiente manera: i) para obtener empleo; ii) para conseguir atención médica o el ingreso a la escuela; iii) para obtener préstamos o créditos; iv) para el cuidado de algún miembro del hogar que se encuentre enfermo; v) para solucionar problema económico grave. Finalmente, como sexto indicador de cohesión social, se indagó si el encuestado ha apoyado con dinero a algún vecino.

En general, se identificó que existe una muy baja vinculación social con los amigos o vecinos de los asentamientos para los primeros cinco indicadores. En las colonias de Iztapalapa y Milpa Alta, cerca del 40\% reportó no recurrir a familiares 
para resolver sus necesidades más inmediatas. A diferencia de las dos anteriores delegaciones, Chimalhuacán mostró una mayor cohesión social, ya que ahí sí indicaron que recurren a familiares para resolver algún problema (53\%). Una posible explicación es que este municipio se ha distinguido por resultados positivos en sus peticiones a través de una organización interna y participación en movimientos sociales urbanos; por ejemplo, en Chimalhuacán, más del $60 \%$ sí recurre a familiares, sobre todo frente a un problema económico grave o para cuidar un pariente enfermo. En las otras colonias, el vínculo es casi inexistente con amigos o vecinos: no más del $9 \%$ se relaciona con ellos (cuadro 10). En el último indicador, apoyo económico a vecinos, en su gran mayoría (más del 60\%), la población de las colonias casi nunca apoya a vecinos con algún recurso financiero. Es decir, la cohesión social está más asociada a lazos de parentesco que a relaciones sociales que se han desarrollado al interior del asentamiento.

CUADRo Io | Estrategias de supervivencia (en porcentajes)

\begin{tabular}{|c|c|c|c|c|c|c|c|c|c|}
\hline \multirow{2}{*}{$\begin{array}{c}\text { TIPO DE } \\
\text { ESTRATEGIAS }\end{array}$} & \multicolumn{3}{|c|}{ IZTAPALAPA } & \multicolumn{3}{|c|}{ MILPA ALTA } & \multicolumn{3}{|c|}{ CHIMALHUACÁN } \\
\hline & $\begin{array}{c}\text { FAMILIA- } \\
\text { RES }\end{array}$ & AMIGOS & $\begin{array}{l}\text { NO TIENEN } \\
\text { A QUIÉN }\end{array}$ & $\begin{array}{c}\text { FAMILIA- } \\
\text { RES }\end{array}$ & AMIGOS & $\begin{array}{l}\text { NO TIENEN } \\
\text { A QUIEN }\end{array}$ & $\begin{array}{c}\text { FAMILIA- } \\
\text { RES }\end{array}$ & AMIgos & $\begin{array}{c}\text { NO } \\
\text { TIENEN } \\
\text { A QUIÉN }\end{array}$ \\
\hline $\begin{array}{l}\text { Apoyo para conse- } \\
\text { guir trabajo }\end{array}$ & 74,2 & 19,4 & 6,5 & 24,7 & 7,9 & 67,4 & 48,7 & 6,7 & 44,5 \\
\hline $\begin{array}{l}\text { Apoyo para } \\
\text { atención médica o } \\
\text { ingreso a la escuela }\end{array}$ & 11,0 & 3,3 & 85,5 & 17,1 & 2,3 & 80,6 & 39,8 & 10,2 & 50,0 \\
\hline $\begin{array}{l}\text { Para obtención } \\
\text { de un préstamo o } \\
\text { crédito }\end{array}$ & 7,7 & 4,3 & 88,0 & 18,2 & 2,3 & 79,5 & 34,7 & 12,7 & 52,5 \\
\hline $\begin{array}{l}\text { Cuidado de inte- } \\
\text { grante del hogar } \\
\text { que esté enfermo }\end{array}$ & 32,5 & 2,6 & 65,0 & 35,6 & 2,3 & 62,1 & 63,6 & 9,3 & 27,1 \\
\hline $\begin{array}{l}\text { A quién recurre } \\
\text { si tiene problema } \\
\text { económico grave }\end{array}$ & 76,8 & 15,2 & 8,0 & 86,0 & 7,0 & 7,0 & 76,9 & 12,8 & 10,3 \\
\hline Promedio & 40,44 & 8,9 & 50,6 & 36,3 & 4,3 & 59,3 & 52,8 & 10,4 & 36,9 \\
\hline
\end{tabular}

Otro aspecto considerado en la medición de la cohesión social fue la participación en actividades para el mejoramiento de la calle y/o barrio. Se identificó al respecto que la participación es muy baja, alcanzando solo a $10 \%$ del total en las siete colonias. Esta participación se concentró en 34 hogares y en ellos se distribuye de la siguiente manera: $44,1 \%$ de hogares participan con trabajo; $11,7 \%$ con dinero; $8,8 \%$ con materiales; $23,5 \%$ participa con los tres anteriores; y 5,8\% reportó participar únicamente a través de la asistencia a las juntas vecinales.

Lo anterior da cuenta del debilitamiento del apoyo social, de la falta de solidaridad o de mecanismos de ayuda recíproca, lo cual se considera como una desventaja importante de la población y muestra su vulnerabilidad económica. Lo anterior parece indicar que el hecho de ayudar a otro vecino implica un gasto extra que se resta al ingreso del hogar, y que la falta de solidaridad social no motiva a destinar 
algún ingreso a la ayuda de terceras personas fuera del hogar, lo que de forma parcial o temporal también implicaría un empobrecimiento del hogar.

\section{Los créditos y el empobrecimiento de los grupos pobres}

Otro aspecto que pone en mayor desventaja a los grupos pobres, es que recurren a los créditos y/o préstamos de alguna institución o empresa. El problema con este tipo de "dinero extra" que adquiere la población es que prolonga su condición de pobreza, por la necesidad de destinar una proporción importante del gasto del hogar a solventar la deuda adquirida en un tiempo determinado. De hecho, solo el 10,6\% de la población encuestada había pedido un préstamo, lo que indica la falta de respaldo económico que tienen estas familias ante cualquier institución de crédito.

Este empobrecimiento se pudo identificar por dos aspectos: primero, conocer a qué destinaron las familias el crédito/préstamo adquirido; y segundo, identificar si, con el préstamo, sus condiciones socioeconómicas mejoraron completa o parcialmente, o si empeoraron o quedaron igual.

En primer lugar, el crédito/préstamo en su gran mayoría fue destinado a mejorar la vivienda; en segundo lugar, a comprar ropa o cosas personales; y en tercer término, hay que destacar que la población usó el dinero del crédito para pagar otras deudas. Por otra parte, cuando se preguntó a los encuestados cuál fue su situación económica después del crédito, mencionaron en su mayoría que sí mejoró su situación (50\% en promedio); en segundo lugar, que solo mejoró parcialmente (40\%); y en tercer lugar, un porcentaje menor quedó endeudado (20\%) (gráfico 1).

\section{GRÁfICO I | Para qué destinaron el crédito/préstamo}

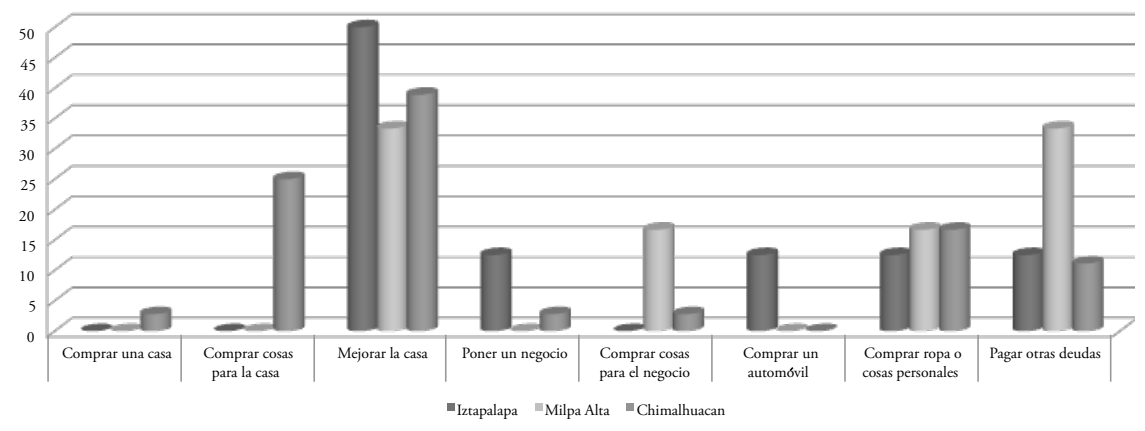

FUENTE ELABORACIÓN PROPIA A PARTIR DE LOS RESULTADOS DE LAS ENCUESTAS APLICADAS A CADA COLONIA

\section{Conclusiones}

El análisis presentado pone en evidencia cómo la diferenciación socioterritorial en la Ciudad de México ha dado lugar a espacios de pobreza de la población en varios asentamientos de la periferia, así como en los suburbios interiores. A través del análisis de una serie de carencias o desventajas, sobre todo de orden social, urbano y económico, se da cuenta de la intensidad de la pobreza en estos lugares. En las colonias 
analizadas, la población experimenta situaciones de profunda privación social, donde las desventajas han tenido un carácter acumulativo y dan lugar a situaciones de alta fragilidad social, las cuales difícilmente permitirán a la población pobre -particularmente aquella de la periferia rural más alejada- salir de esa condición.

Según la medida de pobreza aplicada, seis de las siete colonias muestran condiciones de la pobreza de niveles muy altos. La población vive en un ambiente de pobreza generalizada, con situaciones de precariedad que se manifiestan de manera destacada en los espacios reducidos en sus viviendas, un alto hacinamiento y la falta de acceso a servicios sociales básicos, como salud y educación. En el caso de servicios urbanos, existe una fuerte variación en la presencia de servicios como provisión de agua, drenaje y recolección de basura, e incluso en la calidad de la vivienda. Sin embargo, la existencia de servicios no significa que sean de mejor calidad, ni que las viviendas se encuentren terminadas.

Desde la perspectiva territorial, la población que vive en localizaciones más periféricas está en situación de mayor exclusión social, lo cual se puede identificar por la ausencia de servicios o su inadecuada provisión, y por los bajos ingresos percibidos. Las colonias de la periferia urbana presentan marcadas carencias en prácticamente todos los indicadores; las colonias del suburbio interior tienden a tener mejores indicadores promedio en la consolidación de la vivienda y la presencia de servicios públicos. Pero la periferia rural sistemáticamente tiene las peores condiciones, los ingresos más bajos, las ocupaciones menos calificadas y peor remuneradas y la mayor inseguridad laboral.

La crisis de la sociedad salarial, con la desregulación laboral y el debilitamiento de los esquemas de protección social, son evidentes en los resultados del análisis, que acusan falta de trabajo asalariado, precariedad laboral y bajos ingresos. En su mayoría (un 60\%), la población trabajadora gana por debajo de dos salarios mínimos; existe así alta homogeneidad social, con una muy baja proporción de habitantes que obtiene ingresos medianamente altos. Una gran mayoría de la población no está en condiciones de comprar la canasta básica integral, y ello tanto en la localización periférica como en el suburbio interior, aunque hubo condiciones peores para la periferia rural, donde se advierte un alto nivel de desempleo. La inseguridad laboral a causa de trabajos parciales, temporales y sin contratos formales, es un factor que, junto con la precariedad laboral, agudiza las condiciones de la pobreza, ya que la mayoría de los trabajadores se mueve dentro del mercado informal.

Las situaciones de privación en los asentamientos y la falta de expectativas económicas confirman el aislamiento de los grupos pobres y un debilitamiento de las redes sociales al interior de dichos asentamientos. Se identificó una casi nula vinculación social o ayudas mutuas para resolver problemas urgentes, situación que alcanza mayor gravedad en la periferia rural y el suburbio interior. En este contexto, las posibilidades de solicitud de créditos y/o préstamos son casi inexistentes y, más bien, el empobrecimiento se agrava cuando se recurre a esos mecanismos para pagar otras deudas; de hecho, el dinero así obtenido en la mayoría de los casos no mejora sustancialmente la condición actual.

El propósito de este estudio ha sido enfatizar la existencia y persistencia de espacios pobres dentro de la metrópoli, que en los últimos ańos de la política neoliberal 
han profundizado sus condiciones de pobreza. Estos barrios pobres presentan desventajas que se han acumulado y que se traducen en situaciones de privación en diferentes ámbitos: hacinamiento, bajo nivel educativo, falta de seguridad social, precariedad laboral, bajos ingresos, falta de cohesión social, etcétera. Tales situaciones aparentemente son más graves que en años anteriores, y las posibilidades de superarlas son ciertamente muy difíciles. Consideramos que más que una situación de absoluta exclusión social, de lo que se trata es de una inclusión muy desventajosa, producto de una segmentación de las instituciones por parte del Estado, que es precisamente la que ha dado lugar a esta integración diferenciada de los pobres urbanos, con enormes privaciones.

\section{Referencias bibliográficas}

Aguilar A. G. \& López, F. M. (2013). Poverty in peripheral informal settlements in Mexico City: The case of Magdalena Contreras, Federal District. Tijdschrift voor Economische en Sociale Geografie (Journal of Economic and Social Geography), 104(3), 359-378. doi: 10.1111/tesg. 12012

Ariza, M. \& Solís, P. (2009). Dinámica socioeconómica y segregación espacial en tres áreas metropolitanas de México, 1990-2000. Estudios Sociológicos, 27(79), 171-209. En http://www.redalyc.org/pdf/598/59820689006.pdf

Bayón, M. C. (2008). Desigualdad y procesos de exclusión social. Concentración socioespacial de desventajas en el Gran Buenos Aires y la Ciudad de México. Estudios Demográficos y Urbanos, 23(1), 123-150. En http://www.redalyc.org/articulo.oa?id=31223105

Bayón, M. C. (2009). Oportunidades desiguales, desventajas heredadas. Las dimensiones subjetivas de la privación en México. Espiral. Estudios sobre Estado y Sociedad, 15(44), 163-198. En http://www.redalyc.org/articulo.oa?id=13804405

Bayón, M. C. \& Saraví, G. (2006). Análisis de experiencias nacionales: convergencias y divergencias en América Latina. En G. Saraví (Ed.), De la pobreza a la exclusión: continuidades y rupturas de la cuestión social en América Latina (pp. 55-95). Buenos Aires: Prometeo Libros/México D.F.: Centro de Investigaciones y Estudios Superiores en Antropología Social (CIESAS).

Boltvinik, J. (1997). Aspectos conceptuales y metodológicos para el estudio de la pobreza. En M. Schteingart (Coord.), Pobreza, condiciones de vida y salud en la Ciudad de México (pp. 379-426). México, D.F.: El Colegio de México.

Consejo Nacional de Evaluación de la Política de Desarrollo Social (coneval), México. (2010). Medición de la pobreza. Índice de Rezago Social 2010 a nivel municipal y por localidad. En http://www.coneval.gob.mx/Medicion/Paginas/\%C3\%8Dndice-de-Rezago -social-2010.aspx

Consejo Nacional de Evaluación de la Política de Desarrollo Social (coneval), México. (2013). Medición de la pobreza. Lineas de Bienestar. Valor de la canasta alimentaria. En http:// www.coneval.gob.mx/Medicion/Paginas/Lineas-de-bienestar-y-canasta-basica.aspx [fecha de consulta 11 de diciembre de 2012]. 
Consejo de Evaluación del Desarrollo Social del Distrito Federal (Evalúa DF), México. (2010). Indice de Desarrollo Social de las Unidades Territoriales del Distrito Federal/ IEDS (Delegaciones-Colonias-Manzanas). En http://www.evalua.df.gob.mx/medicionunidades-territoriales-2010.php

Duhau, E. (1998). Hábitat popular y política urbana. México D.F.: Universidad Autónoma Metropolitana-A/Miguel Ángel Porrúa.

Eguía, A. \& Ortale, S. (2004). El estudio de la pobreza en América Latina. Reproducción social y pobreza urbana. Cuestiones de Sociología. Revista de Estudios Sociales, (2), 21-49.

Enríquez Rosas, R. (2003). El rostro actual de la pobreza urbana en México. Comercio Exterior, 53(6), 532-539. En http://revistas.bancomext.gob.mx/rce/magazines/53/4/RCE.pdf

González de la Rocha, M. (2004). De los "recursos de la pobreza" a la "pobreza de los recursos" y a las "desventajas acumuladas". From the marginality of the 1960s to the new poverty of today: A LARR Research Forum, Latin American Research Review, 39(1), 192-195.

González de la Rocha, M. (2006). Vanishing assets: Cumulative disadvantages among the urban poor. En P. Fernández-Kelly \& J. Shefner (Eds.), Out of the shadows. Political action and the informal economy in Latin America (pp. 97-123). University Park, PA: The Pennsylvania State University Press.

Gordon, S. \& Millán, R. (2009). Análisis preliminar de la cohesión social. Un estudio comparativo (Serie Cuadernos de Investigación No 41). México, D.F.: Instituto de Investigaciones Sociales, Universidad Nacional Autónoma de México (UnAM).

Instituto Nacional de Estadística, Geografía e Informática (INEGI), México. (2010). Censo de Población y Vivienda. En http://www.inegi.org.mx/sistemas/consulta_resultados/ageb_ urb2010.aspx?c=28111\&s=est

Instituto Nacional de Estadística, Geografía e Informática (INEGI), México. (2011). Aspectos normativos y metodológicos. Sistema Nacional de Clasificación de Ocupaciones. En http:// www3.inegi.org.mx/sistemas/clasificaciones/sinco/sinco.aspx

Janoschka, M. (2005). El modelo de ciudad latinoamericana. Privatización y fragmentación del espacio urbano de Buenos Aires: El Caso del Nor-delta. En M. Welch Guerra (Ed.), Buenos Aires a la deriva. Transformaciones urbanas recientes (pp. 95-131). Buenos Aires: Biblos.

Kaztman, R. (2001). Seducidos y abandonados: el aislamiento social de los pobres urbanos. Revista de la CEPAL, (75), 171-189. En http://www.cepal.org/publicaciones/ xml/6/19326/katzman.pdf

Kaztman, R. \& Retamoso, A. (2005). Segregación espacial, empleo y pobreza en Montevideo. Revista de la CEPAL, (85), 131-148. En http://www.cepal.org/es/publicaciones/11004segregacion-espacial-empleo-y-pobreza-en-montevideo

Katzman, R. \& Wormald, G. (Coords.) (2002). Trabajo y ciudadanía. Los cambiantes rostros de la integración y la exclusión social en cuatro áreas metropolitanas de América Latina. Montevideo: Cebra/Fundación Ford.

Lewis, O. (1964). Los hijos de Sánchez. México D.F.: Fondo de Cultura Económica.

Lomnitz, L. (1980). Como sobreviven los marginados. $4^{\mathrm{a}}$ ed. México D.F.: Siglo XxI.

Muñoz, H., Oliveira, O. \& Stern, C. (1980). Migración y marginalidad ocupacional en la Ciudad de México. En El Perfil de México en 1980, t. 3 (pp. 325-358). México D.F.: Instituto de Investigaciones Sociales, Universidad Nacional Autónoma de México (UNAM)/Siglo XXI. 
Roberts, B. (2006). La estructuración de la pobreza. En G. Saraví (Ed.), De la pobreza a la exclusión: continuidades y rupturas de la cuestión social en América Latina (pp. 201-232). Buenos Aires: Prometeo Libros/México D.F.: Centro de Investigaciones y Estudios Superiores en Antropología Social (CIESAS).

Saraví, G. A. (2006). Claves para repensar la cuestión social en América Latina. En G. Saraví (Ed.), De la pobreza a la exclusión: continuidades y rupturas de la cuestión social en América Latina (pp. 19-52). Buenos Aires: Prometeo Libros/México D.F.: Centro de Investigaciones y Estudios Superiores en Antropología Social (CIESAS).

Saraví, G. A. (2011). Nuevos escenarios de la pobreza en América Latina. Exclusión y desigualdad. En S. De la Vega Estrada \& G. Juárez (Coords.), Rostros de la pobreza en México. Vistos por distintas disciplinas (pp. 83-106). México D.F.: Universidad Autónoma Metropolitana-Xochimilco.

Servicio de Administración Tributaria (sAT). En http://www.sat.gob.mx/sitio_internet/ asistencia_contribuyente/informacion_frecuente/salarios_minimos/ -fecha de consulta 28 de enero de 2014.

Ward, P. M. (2004). Introduction and overview: Marginality then and now. From the marginality of the 1960s to the new poverty of today: A LARR Research Forum, Latin American Research Review, 39(1), 183-203.

Winchester, L. (2008). La dimensión económica de la pobreza y precariedad urbana en las ciudades latinoamericanas. Implicaciones para las políticas del hábitat. EURE, 34(103), 27-47. http://dx.doi.org/10.4067/S0250-71612008000300002

Ziccardi, A. (2008). Ciudades latinoamericanas: procesos de marginalidad y de exclusión Social. En R. Cordera, P. Ramírez Kuri \& A. Ziccardi (Coords.), Pobreza, desigualdady exclusión social en la ciudad del siglo XXI (pp. 73-91). México D.F.: Universidad Nacional Autónoma de México (UnAm)/Siglo XxI. 
